\title{
CONSIDERAÇÕES SOBRE O TRATAMENTO JURÍDICO DOS ORGANISMOS GENETICAMENTE MODIFICADOS (OGMS) NO BRASIL 10 ANOS APÓS O ADVENTO DA LEI N 11.105 E A PROTEÇÃO DA SAÚDE HUMANA
}

\section{CONSIDERATIONS ON THE LEGAL TREATMENT ON GENETICALLY MODIFIED ORGANISMS (GMOS) IN BRAZIL 10 YEARS AFTER THE ADVENT OF LAW N ${ }^{\circ} 11,105$ AND PROTECTION OF HUMAN HEALTH}

\author{
${ }^{1}$ Mariana Carolina Lemes \\ ${ }^{2}$ Patrícia Nunes Lima Bianchi
}

\section{RESUMO}

No presente artigo busca-se contribuir para os estudos pertinentes aos organismos geneticamente modificados (OGMs), contextualizando essa questão após 10 anos de vigência da Lei $n^{\circ}$ 11.105. Seu objetivo principal é apresentar traços da atual política de OGMs no Brasil, apontando suas principais características e tecendo considerações quanto à possível lesão de direitos difusos, além do comprometimento da proteção da saúde humana, com a análise de decisões exaradas pela CTNBio e a necessidade de sua motivação. Utilizar-se-á o método dialético como método de abordagem. A técnica de pesquisa utilizada foi a documentação indireta, abrangendo a pesquisa documental e a bibliográfica.

Palavras-chave: Organismos geneticamente modificados, Biossegurança, Proteção da saúde humana

\section{ABSTRACT}

The present article seeks to contribute to the relevant studies on genetically modified organisms (GMOs), contextualizing this issue after 10 years of enactment of Law No. 11,105 . Its main objective is to present traces of the current GMO policy in Brazil, pointing its main characteristics, with considerations about the possible injury to diffuse rights, in addition to the commitment of the protection of human health, with the analysis of decision thereof by CTNBio and its motivation. The dialectical method shall be used as method of approach. The research technique used was indirect documentation, including documentary research and literature.

Keywords: Genetically modified organisms, Biosafety, Protection of human health

\footnotetext{
${ }^{1}$ Mestre em Direitos Sociais, Difusos e Coletivos pelo Centro Universitário Salesiano - UNISAL, São Paulo - SP (Brasil). Professora da Faculdade Concórdia - FACC, Concórdia - SC (Brasil).

E-mail: marianakarolinalemes@gmail.com

${ }^{2}$ Doutora em Direito pela Universidade Federal de Santa Catarina - UFSC, Florianópolis - SC. Professora do Centro Universitário Salesiano - UNISAL, São Paulo - SP (Brasil). E-mail: patricianbianchi@ gmail.com
} 


\section{INTRODUÇÃO}

O presente trabalho tem por escopo desenvolver considerações acerca do tratamento jurídico dos organismos geneticamente modificados (OGMs) após 10 anos do termo inicial de vigência da Lei no 11.105/2005 (Lei de Biossegurança).

Trata-se de estudo que estabelece enfoque no processo jurídico de autorização, registro e fiscalização de OGM e derivados, correlacionando a questão com a proteção judicial da saúde e do meio ambiente, com o apontamento dos avanços e retrocessos verificados desde a edição da lei que regulamentou a matéria no país.

Busca-se oferecer uma visão global da legislação atualmente vigente sobre tema, apresentando-se um panorama, das principais preocupações sobre os riscos advindos de OGM e como vêm sendo tratadas estas questões.

O objetivo específico da pesquisa é examinar, ainda que de modo perfunctório, os documentos internacionais e nacionais sobre a matéria e, ainda, o pronunciamento da CTNBio nos seus pareceres técnicos.

A pesquisa busca aclarar a questão do tratamento jurídico dos OGMs no Brasil, ressaltando a importância do tema sob o ponto de vista da tutela geral do meio ambiente, e da tutela coletiva do direito à alimentação adequada e saúde humana. Pretende-se responder ao seguinte problema: como vem sendo tratada a questão dos OGMs no Brasil 10 anos após a edição da Lei ${ }^{\circ} 11.105$ de 2005 ?

A pesquisa traz como hipótese o fato de o tratamento jurídico dos OGMs estar em desacordo com o direito à saúde humana.

Como hipótese secundária pretende-se apontar possíveis lesões ao princípio ambiental da informação.

A abordagem mais ampla do tema será realizada utilizando-se o método dialético, englobando, complementariamente, os métodos: indutivo; e hipotético-dedutivo. A pesquisa será promovida sob três dimensões da dogmática jurídica: uma analítica, uma empírica e uma normativa.

A dimensão analítica se refere à dissecção sistemático-conceitual do direito vigente sobre os OGMs e o direito à saúde humana. Promover-se-á as análises de conceitos elementares (por exemplo, do conceito de OGM e de saúde), passando-se por construções jurídicas (como a relação entre o suporte fático dos direitos fundamentais e suas restrições), até o exame da 
estrutura dos sistema jurídico e da fundamentação relativa ao tema aqui proposto.

A dimensão empírica da dogmática jurídica evidencia-se pela descrição do direito nas leis, aí incluído seu prognóstico na práxis jurisprudencial. Ademais, a efetividade do direito à saúde é objeto da dimensão empírica na medida em que se mostra condição para a validade para a sua concretização por parte da população.

Finalmente, a dimensão normativa lança luzes sobre o que efetivamente pode ser elevado à condição de direito positivo válido, o elucida, e promove sua crítica à práxis jurídica, inclusive jurisprudencial, perscrutando qual a decisão correta em um determinado caso concreto.

No intuito de atingir os propósitos da pesquisa, coletando-se os dados necessários à sua realização, utilizou-se a documentação indireta (abrangendo a pesquisa documental e a bibliográfica). A documentação indireta buscou identificar: (i) os documentos - vigentes ou não - que oferecem contribuição para o desenvolvimento do tema; (ii) a bibliografia existente sobre o assunto - no Brasil e no exterior, de modo a permitir a identificação de eventuais lacunas nos conhecimentos postos, bem como a aplicabilidade de normas internacionais aos problemas identificados.

O trabalho foi organizado em três seções. Na primeira seção tratar-se-á do conceito, da autorização, registro e fiscalização dos OGMs, diferenciando-os dos transgênicos e pormenorizando a legislação vigente sobre o tema delimitado, enquanto na segunda seção cuidar-se-á da proteção legal deferida à saúde humana. Na terceira seção analisar-se-á os pareceres técnicos exarados pela CTNBIo para a autorização e registro dos OGMs no Brasil, evidenciando-se a necessidade de sua motivação, inclusive no que pertine às divergências acerca da necessidade de exames complementares, com a justificação de exames dispensados e de votos contrários.

\section{ORGANISMOS GENETICAMENTE MODIFICADOS (OGMS) NO BRASIL}

Segundo o Ministério da Agricultura, organismos geneticamente modificados são definidos como toda entidade biológica cujo material genético (ADN/ARN) foi alterado por meio de qualquer técnica de engenharia genética, de uma maneira que não ocorreria naturalmente. 
Assim, todo organismo cujo material genético foi manipulado com vistas a favorecer alguma característica desejada é um OGM.

O Decreto no 5.591/2005 define OGM como o "organismo cujo material genético ADN/ARN tenha sido modificado por qualquer técnica de engenharia genética" (Art. $3^{\circ}$, VII) . O inciso VIII do mesmo dispositivo estabelece que se considera derivado de OGM o "produto obtido de OGM e que não possua capacidade autônoma de replicação ou que não contenha forma viável de OGM".

Importante ressaltar que OGM não é um sinônimo de organismos transgênicos, sendo estes espécies daquele. Ou seja, todo transgênico é um OGM, mas nem todo OGM é um transgênico. Transgênicos são os organismos que tiveram introduzidos em si parte do material genético de outro ser.

Sobre o tratamento dos OGMs, verifica-se, no plano internacional, dois documentos de relevo para a compreensão jurídica do tratamento deferido aos OGM: a Convenção sobre Diversidade Biológica (CDB) e o Protocolo de Cartagena.

A CDB de 1992 foi aprovada no Brasil pelo Decreto Legislativo $\mathrm{n}^{\circ}$ 2, de 1994, promulgada pelo Decreto $\mathrm{n}^{\circ} 2.519$, de 1998 , quando passou a ter eficácia também no plano interno brasileiro.

Já o Protocolo de Cartagena de 2000 , é um acordo suplementar adotado pelas partes da $\mathrm{CDB}$, que visa assegurar um nível adequado de proteção no campo da transferência, da manipulação e do uso seguros dos organismos vivos modificados (OVMs) resultantes da biotecnologia moderna, e que possam ter efeitos adversos na conservação e no uso sustentável da diversidade biológica, levando-se em conta os riscos para a saúde humana, decorrentes do movimento transfronteiriço.

O Protocolo reveste-se de importância para o tratamento dos OGMs, como se verifica da explanação a seguir:

\footnotetext{
A adoção do Protocolo pelos países-partes da Convenção constitui-se em um importante passo para a criação de um marco normativo internacional que leva em consideração as necessidades de proteção do meio ambiente, da saúde humana e da promoção do comércio internacional. Cria uma instância internacional para discutir os procedimentos que deverão nortear a introdução de organismos vivos modificados em seus territórios e estabelece procedimento para um acordo de aviso prévio para assegurar que os países tenham as informações necessárias para tomar decisões conscientes antes de aceitarem a importação de organismos geneticamente modificados (OGMs) para seu território. Neste contexto, cabe salientar que o Protocolo incorpora em artigos operativos o Princípio da Precaução, um dos pilares mais importantes desse instrumento e que deve nortear as ações políticas e administrativas dos governos. (Ministério da Agricultura. Organismos
} 
$\begin{array}{lr}\text { geneticamente } & \text { modificados. }\end{array}$

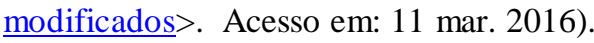

O Protocolo de Cartagena entrou em vigor em 11 de setembro de 2003 e, como pode ser verificado do excerto acima, ressalta a importância do princípio da precaução.

Ainda no âmbito internacional, verifica-se a existência do Protocolo Suplementar de Nagoya-Kuala Lumpur para a solução de questões concernentes à responsabilidade pelos movimentos transfronteiriços de organismos vivos modificados (OVMs) que venham a causar danos. Ressalta-se que o referido protocolo aguarda a ratificação pelo número necessário de Estados partes para exarar todos os seus efeitos na ordem internacional.

No âmbito doméstico, a Constituição Federal de 1988 (CF/88) apresenta diversos dispositivos que podem ser mencionados no presente estudo, dentre os quais pode-se ressaltar o artigo 218, que visa promover e incentivar o desenvolvimento científico, a pesquisa e a capacitação tecnológicas, prevendo a preponderância da pesquisa tecnológica voltada para a solução dos problemas brasileiros e o desenvolvimento do sistema produtivo nacional e regional.

Também merece destaque o artigo 219 da Constituição Federal de 1988, por equiparar o mercado interno a patrimônio nacional e prever o incentivo de seu desenvolvimento, o bem-estar da população e a autonomia tecnológica do País.

Ao tratar do meio ambiente, a Constituição Federal de 1988, em seu artigo 225, caput, prevê o direito fundamental ao meio ambiente ecologicamente equilibrado, bem de uso comum do povo e essencial à sadia qualidade de vida, impondo-se ao Poder Público e à coletividade o dever de defendê-lo e preservá-lo para as presentes e futuras gerações. Em seu $\S 1^{\circ}$, o artigo citado prevê que a asseguração da efetividade desse direito incumbe ao Poder Público, que deverá preservar a diversidade e a integridade do patrimônio genético do país e fiscalizar as entidades dedicadas à pesquisa e manipulação de material genético (inciso II).

No inciso IV do mencionado $\S 1^{\circ}$, o Poder Público resta obrigado, ainda, a exigir na forma da lei, para instalação de obra ou atividade potencialmente causadora de significativa degradação do meio ambiente, estudo prévio de impacto ambiental, a que se dará publicidade. Finalmente, no inciso V, está prevista a obrigação de controle da produção, comercialização e emprego de técnicas, métodos e substâncias que comportem risco para a vida, a qualidade de vida e o meio ambiente. 
Ainda no âmbito da Constituição Federal de 1988 encontra-se outros dispositivos legais de interesse, tal qual o artigo $6^{\circ}$, caput, que inclui o direito à alimentação e o direito à saúde como direitos sociais.

Releva observar que a saúde humana também é objeto do conjunto integrado de ações dos Poderes Públicos e da sociedade e que compreendem a seguridade social. Nesse conjunto integrado de ações devem ser compreendidas à medicina preventiva, de forma a prevenir-se qualquer lesão à saúde dos cidadãos.

Tem-se, ainda, a Lei $\mathrm{n}^{\mathrm{o}}$ 11.105/2005 (Lei de Biossegurança), que disciplina as atividades realizadas com organismos geneticamente modificados, regulamentada pelo Decreto 5.591/2005.

A Lei $n^{\circ} 11.105 / 2005$ substituiu a Lei $n^{\circ} 8.974 / 1995$ e veio regulamentar os incisos II, IV e V do $\S 1^{\circ}$ do art. 225 da Constituição Federal de 1988, estabelecendo normas de segurança e mecanismos de fiscalização de atividades que envolvam OGMs e seus derivados, criando o Conselho Nacional de Biossegurança (CNBS), reestruturando a Comissão Técnica Nacional de Biossegurança (CTNBio) e, dispondo sobre a Política Nacional de Biossegurança $(\mathrm{PNB})$.

De acordo com a legislação brasileira em vigor, o primeiro passo para a emissão de autorização e registro dos OGM é a manifestação da Comissão Técnica Nacional de Biossegurança (CTNBio).

A CTNBio é um órgão colegiado, multidisciplinar, de caráter consultivo e deliberativo que integra o Ministério da Ciência e Tecnologia e presta apoio técnico e de assessoramento ao Governo Federal, com vistas à atualização e implementação da Política Nacional de Biossegurança (PNB) referente aos OGM ${ }^{1}$.

A Comissão também auxilia no estabelecimento de normas técnicas de segurança e na elaboração de pareceres técnicos referentes à autorização para atividades que envolvam a pesquisa e o uso comercial de OGM e derivados, com base na avaliação de seu risco zoofitossanitário, à saúde humana e ao meio ambiente.

A CTNBio é composta por 12 especialistas de notório saber científico e técnico, em efetivo exercício profissional, constituída por 3 profissionais da área de saúde humana, 3 profissionais da área animal, 3 profissionais da área vegetal, 3 da área de meio ambiente, 1 representante de cada um dos seguintes órgãos: MAPA, MCT, MMA, MS, MDIC, MRE, MDA,

\footnotetext{
1 Ministério da Agricultura. Organismos geneticamente modificados. em:〈http://www.agricultura.gov.br/vegetal/organismos-geneticamente-modificados>. Acesso em: 11 mar. 2016.
} 
MD e SEP, 1 especialista em defesa do Consumidor, 1 especialista em Saúde, 1 especialista em Meio Ambiente, 1 especialista em Biotecnologia, 1 especialista em Agricultura Familiar e 1 especialista em Saúde do Trabalhador ${ }^{2}$.

Realizada, portanto, a avaliação do risco zoofitossanitário, à saúde humana e ao meio ambiente, a CTNBio se manifesta pela autorização (ou não) das atividades que envolvam a pesquisa e o uso comercial de OGM e derivados.

Instada a se manifestar, a CTNBio pode requerer que o Conselho Nacional de Biossegurança $^{3}$ analise sob os aspectos de conveniência e oportunidade socioeconômicas e do interesse nacional, os pedidos de liberação para uso comercial de OGM e seus derivados.

O CNBS pode ainda avocar e decidir, em última e definitiva instância, quando julgar necessário, sobre os processos relativos a atividades que envolvam o uso comercial de OGM e seus derivados.

Após essas etapas, compete ao Ministério da Agricultura a emissão de autorizações e registros, bem como a fiscalização de produtos e atividades que utilizem OGM e seus derivados destinados ao uso animal, na agricultura, na pecuária, na agroindústria e áreas afins.

As atividades do Ministério da Agricultura estão sob responsabilidade da Coordenação de Biossegurança, vinculada à Secretaria de Desenvolvimento Agropecuário (SDA).

Ademais, toda entidade que utilizar técnicas e métodos de engenharia genética deverá criar uma Comissão Interna de Biossegurança (CIBio), além de indicar para cada projeto específico um(a) pesquisador(a) principal, definido na regulamentação como principal responsável.

As CIBios são componentes essenciais para o monitoramento e vigilância dos trabalhos de engenharia genética, manipulação, produção e transporte de OGMs e para fazer cumprir a regulamentação de Biossegurança.

Esclarecido o procedimento básico para autorização de OGM, cumpre esclarecer que, nos últimos 20 anos, o volume da produção agrícola cresceu mais de $100 \%$, enquanto a área total plantada aumentou apenas $25 \%$, tendo o setor primário se tornado um dos mais

2 Ministério da Agricultura. Organismos geneticamente modificados. Disponível em: <http://www.agricultura.gov.br/vegetal/organismos-geneticamente-modificados>. Acesso em: 11 mar. 2016.

3 O Conselho Nacional de Biossegurança - CNBS, órgão de assessoramento superior do Presidente da República, criado por meio da Lei $n^{\circ} 11.105$, de 24 de março de 2005, é constituído de 11 Ministros de Estado, com o objetivo de formular e implementar a Política Nacional de Biossegurança - PNB (Ministério da Agricultura. Organismos geneticamente modificados. Disponível em: 〈http://www.agricultura.gov.br/vegetal/organismos-geneticamente-modificados>. Acesso em: 11 mar. 2016). 
competitivos e inovadores, também em razão da utilização da biotecnologia, sendo grande parte do algodão, milho e soja nacionais geneticamente modificados (GM) ${ }^{4}$.

Ocorre que tais padrões internacionais não são tão elucidados como seria de rigor à luz do princípio da informação, mantendo-se a imensa maioria da população ignorante a respeito do fundamento real das autorizações concedidas a empresas como a Monsanto, Bayer entre outras, a ponto de pesquisa realizada pela EMBRAPA demonstrar que a maior parte das pessoas entrevistadas quanto a seu posicionamento sobre os OGMs temem, em geral, os interesses por trás da defesa dos OGMs. ${ }^{5}$

As informações elencadas demonstram que ainda há muito que se aperfeiçoar no procedimento de autorização e comercialização de OGMs. Isso porque, como demonstrado, o princípio da informação ainda não é cumprido a contento pelas agências governamentais, fator que colabora para a perpetuação da ignorância da maior parte da população sobre o tema e minimiza as discussões sobre o tema.

Ao invés de um empoderamento dos cidadãos, a ditadura científica e política mantém a todos os interessados leigos numa posição enfraquecida, impedindo-lhe a emancipação e inviabilizando os debates sobre o tema.

\section{PROTEÇÃO DA SAÚDE HUMANA E OS OGMS}

A pesquisa toma como fundamento o conceito de saúde da Organização Mundial de Saúde (OMS, 1946), segundo a qual saúde seria o completo estado de bem-estar físico, mental e social e não apenas a ausência de doença ou enfermidade, abordando-o a partir de diferentes perspectivas.

\footnotetext{
${ }^{4}$ Nesses termos, o Ministério da Ciência, Tecnologia e Informação manifesta-se no sentido de que as avaliações de segurança dos transgênicos seguem padrões internacionais definidos pela Organização Mundial da Saúde (OMS) e pela Organização das Nações Unidas para Alimentação e Agricultura (FAO/ONU), entidades que já manifestaram apoio aos alimentos GM, a exemplo de outras, como a Academia de Ciências do Vaticano. No Brasil, os OGMs aprovados são submetidos a testes toxicológicos, alergênicos, nutricionais e ambientais que passam pela análise da Comissão Técnica Nacional de Biossegurança (CTNBio), instância colegiada vinculada ao Ministério da Ciência, Tecnologia e Inovação (MCTI). (Ministério da Ciência, Tecnologia e Inovação. Disponível em: 〈http://www.ctnbio.gov.br/upd_blob/0001/1789.pdf>. Acesso em: 13 mar. 2016).

5 "A study conducted in 2011 by the Brazilian Agricultural Research Company (Empresa Brasileira de Pesquisa Agropecuária, Embrapa) on the development of strategic communication on GMO biosafety mentioned that surveys of public opinion in several studies have shown that, in general, people are aware of GMOs, but are suspicious of the "ulterior motives" behind the "defense" of GMOs." In USA. The Law Library of Congress. SOARES, Eduardo. Restrictions on Genetically Modified Organisms: Brazil. Disponível em: <https://www.loc.gov/law/help/restrictions-on-gmos/restrictions-on-gmos.pdf>. Acesso em: 13 mar. 2016.
} 
A saúde foi elevada a direito fundamental ${ }^{6}$ no Brasil apenas com o texto constitucional de 1988, seguindo a tendência européia da Carta italiana, de 1948, e, da Constituição portuguesa, de 1976 (BULOS, 2014, p. 1562).

O art. 196 da Constituição de 1988 estabelece que "a saúde é direito de todos e dever do Estado, garantido mediante políticas sociais e econômicas que visem à redução do risco de doença e de outros agravos e ao acesso universal igualitário às ações e serviços para sua promoção, proteção e recuperação".

No âmbito europeu, a carta dos direitos fundamentais da União Européia trata do direito à integridade (Art. 3.1), estabelecendo que todas as pessoas têm direito ao respeito de sua integridade física e mental, o que vem sendo chamado de direito à integridade psicofísica.

O mesmo documento internacional, ao tratar da proteção da saúde, prevê, em seu artigo 35, que todas as pessoas têm o direito de aceder à prevenção em matéria de saúde e de beneficiar-se de cuidados médicos, de acordo com as legislações e práticas nacionais, determinando-se que na definição e execução de todas as políticas e ações da União Européia, será assegurado um elevado nível de proteção da saúde humana.

A Convenção 155 da OIT, em seu art. 3, “e”, esclarece que, o termo 'saúde', com relação ao trabalho (objeto do documento analisado), abrange não só a ausência de afecções ou de doenças, mas também os elementos físicos e mentais que afetam a saúde e estão diretamente relacionados com a segurança e a higiene no trabalho.

Para BULOS (2014, p. 1562), saúde é o estado de completo bem-estar físico, mental e espiritual do homem, e não apenas a ausência de afecções e doenças, o que leva o autor a afirmar que o "estado de higidez" do indivíduo teria passado a ser (?) destaque na ordem constitucional.

\footnotetext{
${ }^{6}$ Para Alexy (2002, p. 343), “os direitos fundamentais são posições tão importantes que a decisão de protegê-los não pode ser delegada para maiorias parlamentares simples". Eles constituiriam expressão daquilo que o autor denomina "ideia-chave formal", um critério para aquilo que deve ser decidido em conformidade com o processo democrático e aquilo que é decidido pela Constituição, mediante a interpretação de seu conteúdo (Id. 2015, p. 166). Com base em tal teoria, pode-se afirmar que, arrolado um direito como fundamental, este passa a denotar tamanha importância que já não cabe apenas às maiorias parlamentares sobre eles decidir. Ainda segundo Alexy (Ibid., p. 167-169), a tese de dupla natureza dos direitos fundamentais não contesta sejam estes direito positivo ao nível constitucional, gizando, porém, que a positividade é apenas uma de suas características. Isso porque, além da positividade os direitos fundamentais possuem também uma dimensão ideal, na medida em que buscam transformar direitos humanos em direito positivo (lembre-se que, segundo Alexy, direitos fundamentais não possam ser conceituados como direitos humanos positivados). A intenção objetiva de positivar direitos humanos reside no fato de serem estes direitos morais, universais, fundamentais, abstratos, omniprevalecentes. O seu caráter moral (um direito existe se for válido) condiciona a validade dos direitos humanos como direitos morais à sua justificabilidade. Assim, para o autor, os direitos humanos, como direitos morais, pertencem à dimensão ideal do direito, a qual desempenha um papel decisivo na interpretação dos direitos fundamentais como direito positivo. Dessa forma, Alexy conclui que, "a principal expressão dessa decisão é que a dignidade humana justifica o direito a um mínimo existencial” (loc. cit., p. 169).
} 
O conceito utilizado por Bulos se aproxima em muito daquele utilizado pela Organização Mundial de Saúde (OMS) a partir de 1976, definindo a saúde como um "completo estado de bem-estar físico, mental e social e não apenas a ausência de doença ou enfermidade".

Para SEGRE; FERRAZ (1997), a saúde pode ser conceituada como um estado razoável de harmonia entre o sujeito e a sua própria realidade.

Saúde significa o estado de normalidade de funcionamento do organismo humano. Ter saúde é viver com boa disposição física e mental.

Além da boa disposição do corpo e da mente, a OMS (Organização Mundial da Saúde) inclui na definição de saúde, o bem-estar social entre os indivíduos. A saúde de um indivíduo pode ser determinada pela própria biologia humana, pelo ambiente físico, social e econômico a que está exposto e pelo seu estilo de vida, isto é, pelos hábitos de alimentação e outros comportamentos que podem ser benéficos ou prejudiciais. (Significados. Saúde. Disponível em: <http://www.significados.com.br/saude/>. Acesso em: 13 mar. 2016).

A natureza jurídica do direito à saúde qualifica-se como dúplice: (i) direito fundamental que assiste a todas as pessoas e, (ii) conseqüência constitucional indissociável do direito à vida, motivo pelo qual, o Poder Público não pode omitir-se, sob pena de inconstitucionalidade. Nesse sentido, o RE 241.630-2-RS, rel. Min. Celso de Mello, de 3-42001 (apud BULOS, 2014, p. 1562):

O direito à saúde - além de qualificar-se como direito fundamental que assiste
a todas as pessoas - representa conseqüência constitucional indissociável do direito à
vida. O Poder Público, qualquer que seja a esfera institucional de sua atuação no
plano da organização federativa brasileira, não pode mostrar-se indiferente a
problema da saúde da população, sob pena de incidir, ainda que por omissão, em
censurável comportamento inconstitucional. O direito público subjetivo à saúde traduz
bem jurídico constitucionalmente tutelado, por cuja integridade deve velar, de maneira
responsável, o Poder Público (federal, estadual ou municipal), a quem incumbe
formular - e implementar - políticas sociais e econômicas que visem a garantir
a plena consecução dos objetivos proclamados no art. 196 da Constituição da
República (STF, RE $241.630-2 / R S$, Rel. Min. Celso de Mello, DJ, 1, de 3-4-2001, p.
49).

A saúde constitui-se, como se verifica, em direito público subjetivo constitucionalmente tutelado, cuja integridade deve ser velada, e, como direito fundamental, aplicável de forma imediata nos termos do art. $5^{\circ}$ do texto constitucional, devendo ser, portanto, concretizado sem qualquer embaraço. Tal aspecto evidencia as prestações positivas a que se acha obrigado o Poder Público. 
NASCIMENTO (2010, p. 349-350) ressalta ter a Constituição Federal elegido a dignidade da pessoa humana como um dos fundamentos da República (CF, art. 1 ${ }^{\circ}$, II), reservando aos entes autônomos da federação a competência para cuidar da saúde (CF, art. 23, II), frisando que as políticas públicas devem ter sempre como apanágio o princípio da solidariedade, tendo os marcos constitucionais fixado a responsabilidade solidária dos entes públicos.

A natureza da proteção ao direito à saúde pelos entes públicos deve ser considerada como qualificadamente irrenunciável, vez que eventuais normas de cooperação - a serem editadas pela União - não poderiam demitir esta ou os Estados-membros dos encargos constitucionalmente provisionados, evidenciando, assim, as prestações negativas devidas pela Administração.

Não é por outro motivo que eventuais leis estaduais que visem conferir exclusivamente aos Municípios a proteção da saúde são passíveis de controle de constitucionalidade, via ação direta de inconstitucionalidade.

A fixação de competência comum não exige, porém, a atuação simultânea dos níveis federal, estadual e municipal na proteção da saúde, facultando-se à União a edição de espécies normativas que regulem a cooperação. Anote-se, todavia, que nem mesmo as normas assim editadas poderão dispensar o cumprimento dos encargos pela União e pelo Estado-membro, descarregando sobre o Município todo o peso do ônus.

BULOS (2014, p. 1563) assim sintetiza a questão:

Da mesma forma que os direitos sociais em geral $\left(\right.$ art. $\left.6^{\circ}\right)$, o direito à saúde reclama, para sua efetivação, o cumprimento de prestações positivas e negativas. Pela primeira, os Poderes Públicos devem tomar medidas preventivas ou paliativas no combate e no tratamento de doenças. Pela segunda, incumbe-lhe abster-se, deixando de praticar atos obstaculizadores do cabal exercício desse direito fundamental.

Aqui, mais uma vez, o questionamento da população brasileira é no sentido de saber se os Poderes Públicos vêm atuando preventivamente na questão dos OGMs, na busca pela preservação da saúde humana, ou se vêm privilegiando os interesses das empresas beneficiadas pelas autorizações concedidas. 
Assim, conquanto ainda hoje não se possa afirmar se os OGMs têm ou não potencial para causar agravamentos à saúde humana, verifica-se, como variável a possível lesão a direitos como o da alimentação sadia e livre de contaminação intencional, isso em razão da forma como as plantações vêm sendo promovidas. ${ }^{7}$

\section{DA PREVENÇÃO À PRECAUÇÃo (OU SERIA DA PRECAUÇÃO À PREVENÇÃO?): ANÁlISE DO POSICIONAMENTO DO PODER JUDICIÁRIO FRENTE AS DEMANDAS PROPOSTAS}

O princípio da prevenção estabelece que, havendo a comprovação da probabilidade do dano (certeza científica), deve-se abster-se de atuar no sentido de ensejá-lo.

Por seu turno, o princípio da precaução sugere que não se pode esperar dano real ao meio ambiente ou à saúde humana para somente depois reconhecer-se e evitar-se riscos objetivos. Prega, portanto, que nos casos de incerteza científica, atue-se de forma a evitar a geração do dano, deixando-se de praticar o ato.

No caso em estudo, o interesse pela produção dos OGMs encontra resistência pelo desconhecimento acerca das possíveis conseqüências das modificações genéticas, no meio ambiente e na saúde humana, no futuro, devido à ausência de certeza quanto à inexistência de riscos, o que ensejaria a aplicação do princípio da precaução, além do princípio da informação.

Segundo ABRAMOVAY (apud VEIGA et al., 2007, p. 163), da maneira como foi conduzida a questão dos OGM advieram perdas empresariais significativas, as quais devem ser atribuídas à incapacidade das empresas de promoverem uma gestão antecipada da sua contestabilidade.

\footnotetext{
7 Para maiores informações sobre a contaminação de espécies não geneticamente modificadas veja-se o julgamento da Apelação Cível No 5020884-11.2013.4.04.7000 (Processo Eletrônico - E-Proc V2 - TRF4 Região), atualmente em grau de recurso junto ao Superior Tribunal de Justiça (STJ). Disponível em: <https://eproc.trf4.jus.br/eproc2trf4/controlador.php?acao=acessar_documento_publico\&doc=413948132821883 $11110000000773 \&$ evento $=41394813282188311110000000407 \&$ key $=b 095 d 5 b 8606 f c 6832 \mathrm{cde} 69 \mathrm{c} 85 \mathrm{f} 08959568 \mathrm{a}$ 6569dc3ee84a3dd6d7990409407ae >. Acesso em: 12 mar. 2016.
} 
O que se percebe atualmente no Brasil, porém, é que, com o advento da Lei $\mathrm{n}^{\circ}$ 11.105/2005, as empresas têm logrado autorização para a produção e a comercialização de OGMs, sem que se possa verificar se os interesses destas vêm sendo indevidamente privilegiados.Isso porque os sítios do Ministério da Agricultura e do Ministério de Ciência, Tecnologia e Inovação não disponibilizam informações específica sobre dúvidas freqüentes da população sobre os impactos dos OGMs na saúde humana, nem outros esclarecimentos. Limitam-se a cuidar do CNB, do CTNBio, dos laboratórios credenciados, legislação, notícias, orientações técnicas, plantas autorizadas, produtos veterinários biotecnológicos e programas.

Uma vez que, consoante informado no sítio do Ministério da Agricultura, "as avaliações de segurança dos transgênicos seguem padrões internacionais definidos pela Organização Mundial da Saúde (OMS) e pela Organização das Nações Unidas para Alimentação e Agricultura (FAO/ONU)", como já salientado no item 1, supra, foi escolhido, de forma aleatória, o Parecer Técnico no 2956/2011 - Retificado, para leitura e verificação das análises das apreciações de possíveis agravamentos à saúde humana. No documento consta voto divergente no seguinte sentido:

\footnotetext{
Votaram contrariamente ao pleito: Dr. Leonardo Melgarejo, Dra Solange Telles da Silva e Dr. José Maria Gusman Ferraz. O Dr. Leonardo Melgarejo justificou que seu voto fora contrário por considerar que "os estudos não cumprem o item 6 do Artigo 10 da Resolução Normativa $n^{\circ} 5 / 2008$ que em conformidade com o Anexo III exige avaliação de risco à saúde humana e animal compreendendo estudos que outros colegas consideram desnecessários e também porque o item 7 do Art. 10 da RN05 estabelecem exigências com conformidade do Anexo 4 da mesma Resolução Normativa, portanto com base nestas justificativas". A Dra. Solange Telles da Silva justificou que seu voto fora contrário "pelo fato da proposta não estar acompanhada com todos os documentos tal qual disposto na Resolução Normativa $n^{o}$ 05, Artigo 10, Incisos sétimo e sexto”. O Dr. José Maria Gusman Ferraz não justificou a sua declaração de voto.

(_. Ministério da Ciência, Tecnologia e Inovação. CTNBio: rigor e transparência na avaliação de biossegurança de OGM no Brasil. Disponível em:

〈http://www.ctnbio.gov.br/index.php/content/view/16592.html >. Acesso em: 13 mar. 2016).
}

Conforme se lê, um dos experts considerou que os estudos não cumpriam a Resolução Normativa $n^{\circ} 5 / 2008$, que exige avaliação de risco à saúde humana e animal compreendendo estudos que outros colegas consideraram desnecessários. Um dos experts contrários sequer justificou sua declaração de voto contrário.

Da leitura do parecer pode-se verificar que não estão disponíveis as informações necessárias para que a população possa ser sequer melhor esclarecida acerca dos possíveis danos à sua saúde. 
Verifique-se que os estudos complementares não são especificados, nem consta do voto vencedor a justificativa - nem sequer a menção - do porquê de sua dispensa e, a duas, que o expert não necessita nem mesmo justificar o porque de sua contrariedade, havendo uma arbitrariedade.

Ademais, entende-se que as decisões assim exaradas encontram-se em desacordo com o princípio da precaução - que deveria reger a matéria - e consonantes ao princípio da prevenção.

Nesse passo, cumpre relembrar que a biossegurança quantifica e pondera os riscos e benefícios; já a bioética analisa argumentos racionais que justificam, ou não, aqueles riscos. Nesses termos, (GASPARINI, 2009, p. 206) esclarece que

\footnotetext{
A biossegurança, enquanto nova disciplina científica, e a bioética, enquanto nova disciplina filosófica, preocupam-se com esta nova situação, tentando ponderar os prós e os contras, e se for o caso, propor leis, normas e diretrizes com o intuito de minimizar riscos, abusos, conflitos e controvérsias, sem prejudicar, entretanto, os avanços biotecnocientíficos.
}

$\mathrm{Na}$ hipótese vertente, tem-se que a biossegurança e a bioética não vêm sendo consideradas pelos membros da CTNBio, que vêm privilegiando os interesses das empresas na autorização e comercialização dos OGMs, negando informações e direitos à população brasileira.

Imprescindível, portanto, o controle - especialmente o judicial - dos atos administrativos (pareceres) da CTNBio, para apreciação de lesão ou perigo de lesão à saúde humana em razão das omissões denunciadas.

\section{CONCLUSÕES}

Com o término do presente trabalho logrou-se apresentar os principais documentos atualmente vigentes no ordenamento jurídico, tratando-se das principais regulamentações sobre OGMs no Brasil hoje, 10 anos após a edição da Lei no 11.105 (Lei de Biossegurança).

Tendo em vista a complexidade do tema, optou-se por refletir sobre aspectos mais gerais, não se olvidando de assuntos considerados fundamentais, como, por exemplo, como e em que medida vêm sendo autorizados e registrados os OGMs no Brasil, com a análise de decisões exaradas pela CTNBio e a necessidade de sua motivação, inclusive no que pertine às 
divergências acerca da necessidade de exames complementares, com a justificação de exames dispensados e de votos contrários.

Procurou-se investigar possível repercussão e lesão ao direito à saúde humana, mais especialmente o controle dos atos administrativos exarados pela CTNBio.

Os dados obtidos e as hipóteses enunciadas refletem a importância da cooperação internacional no fortalecimento de capacidades técnicas e jurídicas em matéria de biotecnologia e biossegurança de OGM, bem como da concretização do princípio da informação.

A ausência de motivação nas decisões exaradas pelos especialistas da CTNBio estaria a demonstrar que a biossegurança e a bioética não vêm sendo consideradas pelos seus membros, podendo ser apontado tal fato como fonte de intranqüilidade e preocupação da população, no sentido de estar-se privilegiando os interesses das empresas na autorização e comercialização dos OGMs, negando informações e direitos à população brasileira.

A motivação obrigatória de todas as decisões, inclusive dos pareceres contrários, aparece como suficiente para, ao menos no presente momento, privilegiar os interesses difusos envolvidos, devendo a responsabilidade dos membros da CTNBio ser aferida nos casos em que a autorização for concedida em desacordo com os parâmetros legais existentes e na hipótese de privilegiar-se os interesses empresariais em detrimento dos direitos dos cidadãos.

\section{REFERÊNCIAS}

ALEXY, Robert. A Theory of Constitucional Rights (trad. Julian Rivers). Oxford: Oxford University Press, 2002, p. 343.

BRASIL. Constituição da República Federativa do Brasil de 1988. Disponível em: <http://www.planalto.gov.br/ccivil_03/Constituicao/Constituicao.htm>. Acesso em: 12 mar. 2016.

Convenção sobre diversidade biológica. Disponível em:

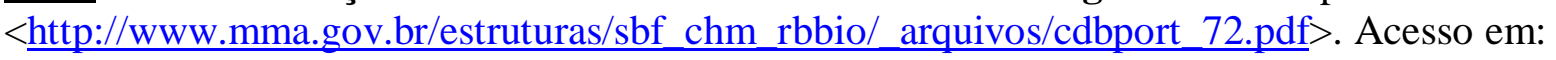
11 mar. 2016.

. Ministério da Ciência, Tecnologia e Inovação. CTNBio: rigor e transparência na avaliação de biossegurança de OGM no Brasil. FINARDI FILHO, Flavio. Disponível em: <http://www.ctnbio.gov.br/upd_blob/0001/1789.pdf>. Acesso em: 13 mar. 2016. 
Decreto $\mathbf{n}^{\mathbf{0}}$ 5.591, de 22 de novembro de 2005. Regulamenta a Lei $\mathrm{n}^{\mathrm{o}}$ 11.105/2005. Disponível em: <http://www.planalto.gov.br/ccivil_03/_ato20042006/2005/Decreto/D5591.htm>. Acesso em: 11 mar. 2016.

Lei $\mathbf{n}^{\mathbf{0}}$ 8.974, de 5 de janeiro de 1995. Revogada.Disponível em: <http://www.planalto.gov.br/ccivil_03/leis/L8974.htm>. Acesso em: 11 mar. 2016.

Lei $\mathbf{n}^{\mathbf{0}}$ 11.105, de 24 de março de 2005. Lei de Biossegurança. Disponível em: <http://www.planalto.gov.br/ccivil_03/_ato2004-2006/2005/lei/111105.htm>. Acesso em: 11 mar. 2016.

. Ministério da agricultura. Organismos geneticamente modificados. Disponível em: $\langle$ http://www.agricultura.gov.br/vegetal/organismos-geneticamente-modificados $>$. Acesso em: 11 mar. 2016.

Tribunal Regional Federal da $4^{\mathbf{a}}$ Região. Apelação Cível $\mathrm{N}^{\mathrm{o}}$ 502088411.2013.4.04.7000 (Processo Eletrônico - E-Proc V2 - TRF4 ${ }^{a}$ Região), atualmente em grau de recurso junto ao Superior Tribunal de Justiça (STJ). Disponível em:

$<$ https://eproc.trf4.jus.br/eproc2trf4/controlador.php?acao=acessar_documento_publico\&doc= $41394813282188311110000000773 \&$ evento $=41394813282188311110000000407 \& \mathrm{key}=\mathrm{b} 095$ d5b8606fc6832cde69c85f08959568a6569dc3ee84a3dd6d7990409407ae >. Acesso em: 12 mar. 2016.

BULOS, Uadi Lammêgo. Curso de Direito Constitucional. 8 ed. São Paulo: Saraiva, 2014.

CANADÁ. Protocolo de Cartagena. Disponível em: 〈http://bch.cbd.int/protocol/text/>. Acesso em: 11 mar. 2016.

. Protocolo Suplementar de Nagoya-Kuala Lumpur. Disponível em:

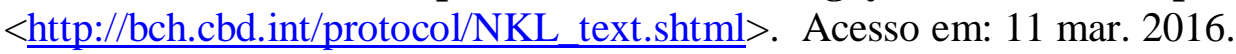

GASPARINI, Bruno et al. Transgenia na agricultura. Curitiba: Juruá, 2009.

NASCIMENTO, Carlos Valder do. Direito fundamental à saúde. In: MARTINS, Ives Gandra da Silva; MENDES, Gilmar Ferreira; NASCIMENTO, Carlos Valder do. (Coord.). Tratado de Direito Constitucional. vol. 2. São Paulo: Saraiva, 2010, p. 349-402.

OMS. Health. Disponível em: 〈http://www.who.int/trade/glossary/story046/en/>. Acesso em: 13 mar. 2016.

ORGANIZAÇÃO INTERNACIONAL DO TRABALHO (OIT). Convenção no 155, de 22-61981. Disponível em: 〈http://www.oitbrasil.org.br/node/504>. Acesso em: 30 out. 2015. Genebra, 1981.

SEGRE, Marco; FERRAZ, Flávio Carvalho. O conceito de saúde. Rev. Saúde Pública, São Paulo, v. 31, n. 5, p. 538-542, Oct. 1997. Disponível em:

<http://www.scielo.br/scielo.php?script=sci_arttext\&pid=S0034-89101997000600016 $>$. Acesso em: 28 out. 2015. 
SIGNIFICADOS. Saúde. Disponível em: 〈http://www.significados.com.br/saude/>. Acesso em: 13 mar. 2016.

USA. The Law Library of Congress. SOARES, Eduardo. Restrictions on Genetically Modified Organisms: Brazil. Disponível em: <https://www.loc.gov/law/help/restrictions-ongmos/restrictions-on-gmos.pdf>. Acesso em: 13 mar. 2016.

VEIGA, José Eli da. Transgênicos: sementes da discórdia. São Paulo: Editora Senac São Paulo, 2007. 